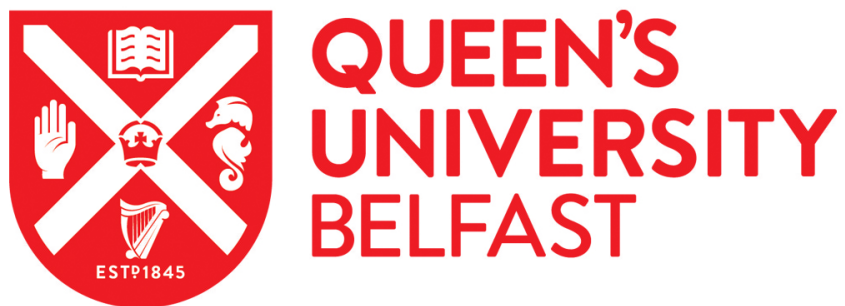

\section{The effect of polymer coatings on physicochemical properties of spray-dried liposomes for nasal delivery of BSA}

Chen, K. H., Di Sabatino, M., Albertini, B., Passerini, N., \& Kett, V. L. (2013). The effect of polymer coatings on physicochemical properties of spray-dried liposomes for nasal delivery of BSA. European Journal of Pharmaceutical Sciences, 50(3-4), 312-322. https://doi.org/10.1016/j.ejps.2013.07.006

Published in:

European Journal of Pharmaceutical Sciences

Document Version:

Peer reviewed version

Queen's University Belfast - Research Portal:

Link to publication record in Queen's University Belfast Research Portal

Publisher rights

(c) 2015, Elsevier. Licensed under the Creative Commons Attribution-NonCommercial-NoDerivatives 4.0 International

http://creativecommons.org/licenses/by-nc-nd/4.0/ which permits distribution and reproduction for non-commercial purposes, provided the author and source are cited.

\section{General rights}

Copyright for the publications made accessible via the Queen's University Belfast Research Portal is retained by the author(s) and / or other copyright owners and it is a condition of accessing these publications that users recognise and abide by the legal requirements associated with these rights.

Take down policy

The Research Portal is Queen's institutional repository that provides access to Queen's research output. Every effort has been made to ensure that content in the Research Portal does not infringe any person's rights, or applicable UK laws. If you discover content in the Research Portal that you believe breaches copyright or violates any law, please contact openaccess@qub.ac.uk. 


\section{Accepted Manuscript}

The effect of polymer coatings on physicochemical properties of spray-dried liposomes for nasal delivery of BSA

K.H. Chen, M. Di Sabatino, B. Albertini, N. Passerini, V.L. Kett

PII:

S0928-0987(13)00260-1

DOI:

http://dx.doi.org/10.1016/j.ejps.2013.07.006

Reference:

PHASCI 2819

To appear in:

European Journal of Pharmaceutical Sciences

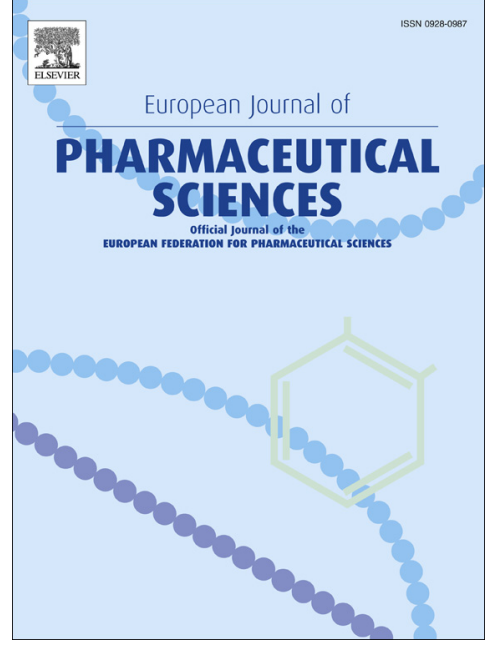

Received Date: $\quad 17$ January 2013

Revised Date: $\quad 27$ June 2013

Accepted Date: $\quad 10$ July 2013

Please cite this article as: Chen, K.H., Di Sabatino, M., Albertini, B., Passerini, N., Kett, V.L., The effect of polymer coatings on physicochemical properties of spray-dried liposomes for nasal delivery of BSA, European Journal of Pharmaceutical Sciences (2013), doi: http://dx.doi.org/10.1016/j.ejps.2013.07.006

This is a PDF file of an unedited manuscript that has been accepted for publication. As a service to our customers we are providing this early version of the manuscript. The manuscript will undergo copyediting, typesetting, and review of the resulting proof before it is published in its final form. Please note that during the production process errors may be discovered which could affect the content, and all legal disclaimers that apply to the journal pertain. 
The effect of polymer coatings on physicochemical properties of spray-dried liposomes for nasal delivery of BSA.

K.H. Chen ${ }^{1}$, M. Di Sabatino ${ }^{2}$, B. Albertini ${ }^{2}$, N. Passerini ${ }^{2}$, V.L. Kett ${ }^{1 *}$.

1. School of Pharmacy, Queen's University Belfast, 97 Lisburn Road, Belfast, UK, BT9 7BL

2. Department of Pharmacy and Biotechnology, University of Bologna, Bologna, Italy

*Corresponding Author email v.kett@qub.ac.uk tel. +44(0)2890 972008

Abstract: This work describes the development of spray dried polymer coated liposomes composed of soy phosphatidylcholine (SPC) and phospholipid dimyristoyl phosphatidylglycerol (DMPG) coated with alginate, chitosan or trimethyl chitosan (TMC), that are able to penetrate through the nasal mucosa and offer enhanced penetration over uncoated liposomes when delivered as a dry powder. All the liposome formulations, loaded with BSA as model antigen, were spray-dried to obtain powder size and liposome size in a suitable range for nasal delivery. Although coating resulted in some reduction in encapsulation efficiency, levels were still maintained between $60-69 \%$ and the structural integrity of the entrapped protein and its release characteristics were maintained. Coating with TMC gave the best product characteristics in terms of entrapment efficiency, glass transition ( $\mathrm{Tg}$ ) and mucoadhesive strength, while penetration of nasal mucosal tissue was very encouraging when these liposomes were administered as dispersions although improved results were observed for the dry powders.

Keywords; nasal, mucosal, liposomes, spray-dried, protein, glass transition, trimethyl chitosan 


\section{Introduction}

Nasal drug delivery has been recognized as a very promising route for drug delivery and antigen delivery in particular since the nasal cavity offers a highly vascularized epithelium, large surface area available for drug absorption, relatively lower rates of enzymatic degradation in comparison with the oral route, as well as the potential for systemic delivery (Pires et al., 2009). However bioavailability may be as low as $10 \%$ for some small polar drugs and less than $1 \%$ for large molecules (O'Hagan and Illum, 1990) because of the presence of mucus and the mucociliary clearance (MCC) mechanism (Illum, 2003). Moreover degradation in the lumen of the nasal cavity or during the passage across the nasal epithelia barrier can affect negatively the bioavailability of active substances due to the presence of a wide spectrum of metabolic enzymes in nasal tissues (Dimova et al., 2005; Lee and Yamamoto, 1990; Mitra and Krishnamoorthy, 1998).

Liposomes have been extensively investigated for the nasal delivery of proteins; advantages include their protective effect on entrapped protein (Kato et al., 1993; Murramatsu et al., 1999), the ability to cause mucosal membrane disruption (Lee et al., 1991) and the capability of positively charged liposomes to increase residence time at the negatively charged mucosal surface (Law et al., 2001). Unfortunately they are easily removed by MCC. Conversely mucoadhesive polymers can retard the MCC rate but often lack penetration ability offering little improvement in the absorption of hydrophilic and/or large molecules.

Mucoadhesive formulations have been demonstrated to improve the absorption of nasally administered drugs by prolonging the contact duration between drug and nasal mucosa (Gavini et al., 2008, Patil and Sawant, 2009; Ugwoke et al., 2005). Chitosan's positively charged groups can form strong ionic interactions with acidic sialic moieties of mucins, leading to strong mucoadhesion (Bonferoni et al., 2006; Luppi et al., 2010) and can promote the transmucosal absorption of small polar molecules as well as peptide and protein drugs from nasal epithelia (Artursson et al., 1994; Illum et al., 1994), which has been attributed to its capability to open tight junction complexes (Smith et al., 2004) and also to induce redistribution of F-actin (Dodane et al., 1999). However environmental pH has a 
marked influence on the permeation capability of chitosan/ chitosan salts (Borchard et al., 1996). Trimethyl chitosan (TMC) and other substituted chitosans have been synthesized (Avadi et al., 2004, 2003; Bayat et al., 2006; Sieval et al., 1998); the degree of quaternization of TMC determines the amount of positive charges available for interaction and thereby influences its drug absorption-enhancing properties and has been shown to improve the paracellular permeability of intestinal epithelia (Thanou et al., 2000). TMC has been investigated for the nasal delivery of proteins and antigens with encouraging results (Amidi et al., 2007, 2006), that have been correlated with the strength of the cationic charge of the polymer (Sadeghi et al., 2008). Among other mucoadhesive polymers, alginates are anionic water-soluble linear polysaccharides that have been widely investigated in mucoadhesive formulations due to their ability to form hydrogen bonds with mucin-type glycoproteins through carboxyl-hydroxyl interactions. Alginates have been investigated for the nasal delivery of actives and it was found that polyanion polymers are more effective bioadhesives than polycation or nonionic polymers (Bernkop-Schnurch 2002; Braccini and Perez, 2001).

Coating liposomes with mucoadhesive polymers can result in increased bioavailability, as previously demonstrated by Jain et al. (2007). Furthermore, formulating liposomes as a powder rather than as a dispersion enables easier application and improved stability over liquids and dried mucoadhesive powders can be more effective than dispersions (Dyer et al., 2002; Gill et al., 1998; Illum et al., 2000; Wang et al., 2006).

Thus, in this study we have aimed to combine the merits of these approaches (liposome formulation and mucoadhesion) to produce spray-dried polymer-coated liposomes for nasal delivery of antigen. Bovine serum albumin (BSA) was used as a model antigen and chitosan, TMC and alginate were evaluated as liposome coating polymers. Uncoated and polymer coated liposome formulations were compared with their corresponding spray-dried liposome powders. The objective of this study is to achieve spray dried BSA-loaded liposomes with high encapsulation efficiency, protection of the protein structure, mucoadhesive properties and penetration across the nasal mucosa.

\section{Materials and methods}




\subsection{Materials}

Soy phosphatidylcholine (LIPOID S 75, 80\%), soy phosphatidylcholine (LIPOID S PC, >98\%) and phosphatidyl glycerol-Na (DMPG-Na >99\%) were obtained from Lipoid (Steinhausen, Switzerland). Cholesterol (PhEur grade), bovine serum albumin (BSA) (Fraction V, lyophilized powder), dithiothreitol (DTT), L-leucine (PhEur grade), trifluoroacetic acid (99\%), iron (III) chloride hexahydrate ( $\geq 99 \%$ ), alginate (sodium salt from brown algae, medium viscosity), chitosan (medium molecular weight, $75-85 \%$ deacetylated, $200-800$ cP (1 wt. \% in 1\% acetic acid), iodomethane ( $\geq 99.0 \%)$, mucin (porcine stomach, Type III, bound sialic acids around $1 \%)$, albumin-fluorescein isothiocyanate conjugate (FITC-BSA), sodium iodide ( $\geq 99.0 \%), 1$ methyl-2-pyrrolidone (99\%), sodium hydroxide (PhEur grade), polyvinyl alcohol mounting medium with $\mathrm{DABCO}{ }^{\circledR}$, ammonium thiocyanate $(\geq 99.0 \%)$, stearylamine and propidium iodide $(\geq 94.0 \%)$ were purchased from Sigma-Aldrich (Poole, UK). $\alpha, \alpha$-trehalose dehydrate (high purity, low endotoxin) was obtained from FERRO Pfanstiehl (Mayfield Heights, USA). Tris (hydroxyl methyl) methylamine AanlaR ${ }^{\circledR}$ (99\%) was from VWR (Lutterworth, UK). SDSPAGE loading dye buffer, NuPAGE Novex Bis-Tris (4-12\%) minigel, SDS-MOPS running buffer, NUPAGE ${ }^{\oplus}$ antioxidant and Simply blue stain were obtained from Invitrogen (Paisley, UK). Tissue-Tek® OTC ${ }^{T M}$ Compound was purchased from Sakura Finetek UK Ltd (Thatcham, UK).

Fresh bovine nasal tissue was obtained from a local slaughterhouse and used immediately. All organic solvents were of HPLC grade and all aqueous solutions were prepared with freshly de-ionized water.

\subsection{Methods}

\subsubsection{Preparation of uncoated liposomes}

The liposomal dispersions, whose compositions are reported in Table 1, were prepared by dispersing vesicular phospholipid gels (VPGs) using the method developed by Massing et al. (2008). BSA and lipid components were homogenized with the same mass of hydration medium (25 mM Tris $\mathrm{HCl}$ containing 15\% (w/w) trehalose dihydrate) using a dual asymmetric centrifuge (Speed-Mixer ${ }^{\mathrm{TM}}$ DAC $150 \mathrm{FVZ}$, Germany). The centrifugation speed of each cycle was maintained at 3,500 rpm for 5 min followed by 2 min rest in an ice bath to avoid heating. The process was performed 15 times. VPGs were converted to liposomal suspensions by dropwise addition of the rest of hydration medium and simultaneous stirring. Then, 
liposomal dispersions were continuously stirred for 2 hours in a cold room. The liposome dispersions were either polymer-coated or spray dried directly. Spray drying was performed with a Mini-Spray-dryer (Büchi 190; Flawil, Switzerland). Applied spray parameters were: inlet temperature $100{ }^{\circ} \mathrm{C}$, outlet temperature $68^{\circ} \mathrm{C}$, air-flow $600-650 \mathrm{NI} / \mathrm{h}$, aspirator setting 20 (100\%), pump setting 2.5-3 ml/min. A 0.5-mm nozzle was used (Chen et al., 2012). Characterisation for lipid content, size, zeta potential and encapsulation efficiency were performed on fresh samples.

\subsubsection{Liposome optimization for spray drying: determination of optimum trehalose} concentration

For the preparation of an initial vesicular phospholipid gel (VPG) $25 \mathrm{mM}$ Tris $\mathrm{HCl}$ containing either 5,10 or $15 \%(\mathrm{w} / \mathrm{w})$ trehalose dihydrate was used as the hydration medium. Subsequently, $5 \%(\mathrm{w} / \mathrm{w})$ trehalose dihydrate solution was dropwise added into this VPG and then it progressively turned into liposome suspensions. Unentrapped BSA was separated by ultracentrifugation at 90,000 $\mathrm{rpm}$ then washing and resuspending the liposome pellets twice (Takeuchi et al., 2005). Finally, the liposome pellets were dispersed in hydration media containing $0.2 \%(\mathrm{w} / \mathrm{w})$ leucine, as anti-adherant as previously (Chen et al., 2012) and either 5,10 or $15 \%(w / w)$ trehalose, before 4 -fold dilution with the same hydration medium prior to spray drying.

\subsubsection{Synthesis and characterization of TMC}

TMC was synthesized by reductive methylation of the chitosan with methyl iodide in the alkaline condition using the procedure described by Polnok et al. (2004) with some modification. In step 1, $0.5 \mathrm{~g}$ of chitosan, $1.2 \mathrm{~g}$ of sodium iodide, $2.5 \mathrm{ml}$ of $20 \%$ aqueous sodium hydroxide and $20 \mathrm{ml}$ of $\mathrm{N}$-methylpyrrolidone were heated in a water bath at $60{ }^{\circ} \mathrm{C}$ for $10 \mathrm{~min}$. Subsequently, $3 \mathrm{ml}$ of iodomethane was added to the mixture and the reaction was carried out for $90 \mathrm{~min}$ in a reflux condenser. The polymer was precipitated from using ethanol and centrifugation, and then washed twice with diethyl ether. In reaction step 2, the product from the previous step was mixed with $1.2 \mathrm{~g}$ of sodium iodide, $2.5 \mathrm{ml}$ of $20 \%$ sodium hydroxide and $20 \mathrm{ml}$ of $\mathrm{N}$-methylpyrrolidone at $60{ }^{\circ} \mathrm{C}$ for $10 \mathrm{~min} .3 \mathrm{ml}$ of iodomethane was added to the mixture and the reaction was carried out for $90 \mathrm{~min}$ in a reflux condenser. The product was precipitated and washed as described above. The 
product from step 2 was dissolved in $100 \mathrm{ml}$ of $10 \%(\mathrm{w} / \mathrm{v})$ sodium chloride solution to exchange the iodide ion with chloride, and stirred overnight before dialysis and subsequent freeze-drying.

The synthesized polymer was characterized by infrared (IR) and proton nuclear magnetic resonance $\left({ }^{1} \mathrm{H}-\mathrm{NMR}\right)$ spectroscopy. The IR spectra of chitosan and TMC were obtained on pellets formed by grinding mixtures of the polymer with $\mathrm{KBr}$ before compression, analyses was performed across the range $400 \mathrm{~cm}^{-1}-4000 \mathrm{~cm}^{-1}$ using a Fourier Transform Infrared Spectrophotometer model 4100 (FT/IR-4100) (Jasco, Great Dunmow, UK). ${ }^{1} \mathrm{H}-\mathrm{NMR}$ spectra of the TMC samples were obtained with an NMR spectrometer (AVIII-400, Bruker, Switzerland) by hydrating samples of the polymers in $\mathrm{D}_{2} \mathrm{O}$ at $80^{\circ} \mathrm{C}$ with suppression of the water peak. The degree of quaternization (DQ) was calculated using data obtained from the ${ }^{1} \mathrm{H}-\mathrm{NMR}$ spectra according to the following Eq. (1).

$\% \mathrm{DQ}=\left[\left(\mathrm{CH}_{3}\right)_{3}\right] /[\mathrm{H}] \times(100 / 9)$ Equation 1

Where $\left[\left(\mathrm{CH}_{3}\right)_{3}\right]$ is the integral of trimethyl amino group at $3.3 \mathrm{ppm}$. $[\mathrm{H}]$ is the integral of ${ }^{1} \mathrm{H}$ peaks between 4.7 and $5.7 \mathrm{ppm}$.

\subsubsection{Preparation of polymer-coated liposome powders}

Polymer dispersions with concentrations calculated on the basis of the same mole charge ratio were used to coat the liposomes. $0.25 \%(\mathrm{w} / \mathrm{w})$ alginate and $0.5 \%(\mathrm{w} / \mathrm{w})$ TMC dispersions were prepared by hydrating them with $25 \mathrm{mM}$ Tris $\mathrm{HCl}$ buffer containing $10 \%$ $(\mathrm{w} / \mathrm{w})$ trehalose dihydrate and $0.2 \%(\mathrm{w} / \mathrm{w})$ L-leucine. $0.25 \%(\mathrm{w} / \mathrm{w})$ chitosan dispersion was prepared by hydrating with $100 \mathrm{mM}$ acetate buffer $(\mathrm{pH}$ 5.0) containing $10 \%(\mathrm{w} / \mathrm{w})$ trehalose dihydrate and $0.2 \%(\mathrm{w} / \mathrm{w})$ L-Leucine. Liposomal dispersions in $10 \%(\mathrm{w} / \mathrm{w})$ trehalose/0.2\% $(\mathrm{w} / \mathrm{w})$ L-leucine prepared as in 2.2.1 were subjected to ultracentrifugation as in 2.2.2 to remove free $B S A$, were added dropwise into the desired polymer dispersion at 1:4 $(\mathrm{w} / \mathrm{w})$ ratio of liposome dispersion to polymer dispersion. The dispersions were continuously stirred at $900 \mathrm{rpm}$ for $2 \mathrm{~h}$ on ice before spray-drying. For the chitosan-coated and TMCcoated liposomes an additional procedure of short period of 2.5 min sonication (10 sec sonication/10 sec rest on ice bath) was applied following the coating procedure in order to reduce the liposomal size as has been described previously (Thongborisute et al., 2006). Spray drying conditions for all liposomes were as described for the uncoated liposomes. 


\subsubsection{Lipid content, size and zeta potential analysis}

Lipid content, expressed as phospholipid concentrations, was assessed by first extracting the lipids according to the method of Bligh and Dyer (1959) and then performing the Stewart assay (Stewart, 1980). Liposome size and Zeta potential were determined with a ZetaSizer $3000 \mathrm{HS}$ (Malvern Instruments, Malvern, UK) at a temperature of $25 \pm 0.1^{\circ} \mathrm{C}$. Uncoated-, alginate- and TMC- coated liposomes were dispersed into $2.5 \mathrm{mM}$ Tris HCl buffer of $\mathrm{pH} 7.2$ while chitosan-coated liposomes were dispersed into $2.5 \mathrm{mM}$ acetate buffer of $\mathrm{pH}$ 5.0. For size analysis, 4 replicate measurements were performed. Zeta potential was measured 10 times; values are reported as mean \pm standard deviation.

\subsubsection{Encapsulation efficiency of BSA}

The encapsulation efficiency (EE\%) of BSA entrapped in the liposome and polymer-coated liposomal dispersions was calculated based on the ratio of encapsulated to total BSA concentration. Entrapped BSA was calculated by subjecting dispersions to ultracentrifugation at 90,000 rpm (Beckman Coulter Optima TLX-120 Ultracentrifuge, High Wycombe, UK) for one hour at $4^{\circ} \mathrm{C}$ and then determining the concentration of free BSA in the supernatant by using HPLC. Total BSA content was determined by dilution then membrane disruption using isopropanol followed by HPLC analysis as below.

\subsubsection{HPLC method for analysis of BSA}

Reverse phase HPLC method was used for quantification of BSA with some modification of the conditions by Umrethia et al. (2010). HPLC was carried out using a Waters system (Waters 1525 Binary HPLC Pump, Waters IN-Line Degasser AF, Waters 2487 Dual $\lambda$ Absorbance Detector, Waters 717 plus Autosampler, Waters, Milford, USA). Jupiter C-5 column ( $300 \mathrm{~A}^{\circ}, 250 \times 4.6 \mathrm{~mm} 5 \mu \mathrm{m}$, Phenomenex, Torrance, USA) was used at $30^{\circ} \mathrm{C}$ and the detector was set to $220 \mathrm{~nm}$. The mobile phase consisted of a gradient of $0.2 \%$ TFA in acetonitrile (A) and 0.2\% TFA in water (B). The gradient schedule was: (a) 0-20 min, $A / B=5: 95$ $(\mathrm{v} / \mathrm{v}) \rightarrow A / B=65: 35(\mathrm{v} / \mathrm{v})$, flow rate of $1 \mathrm{ml} / \mathrm{min}$; (b) 20-23 $\mathrm{min}, A / B=65: 35(\mathrm{v} / \mathrm{v}) \rightarrow 100 \%(\mathrm{v} / \mathrm{v})$ A, flow rate of $1 \mathrm{ml} / \mathrm{min}$; (c) $23-24.5 \mathrm{~min}, 100 \%$ (v/v) A, flow rate of $1 \mathrm{ml} / \mathrm{min} \rightarrow 1.5 \mathrm{ml} / \mathrm{min}$; 
(d) $24.5-30.5 \mathrm{~min}, 100 \%(\mathrm{v} / \mathrm{v}) \mathrm{A}$, flow rate of $1.5 \mathrm{ml} / \mathrm{min}$; (e) $30.5-31 \mathrm{~min}, 100 \%$ (v/v) A, flow rate of $1.5 \mathrm{ml} / \mathrm{min} \rightarrow 1 \mathrm{ml} / \mathrm{min}$; (f) 31-34 $\mathrm{min}, 100 \%(\mathrm{v} / \mathrm{v}) \rightarrow A / B=5: 95(\mathrm{v} / \mathrm{v})$, flow rate of 1 $\mathrm{ml} / \mathrm{min}$; (g) 34-44 $\mathrm{min}, A / B=5: 95(\mathrm{v} / \mathrm{v})$, flow rate of $1 \mathrm{ml} / \mathrm{min}$.

\subsubsection{Effect of Processing on BSA integrity and secondary structure}

The integrity of BSA in the liposomes following processing was analysed using SDS-PAGE. The dispersions were diluted until a concentration of $\sim 50 \mu \mathrm{g} / \mathrm{ml}$ of BSA was obtained. A 13 $\mu \mathrm{l}$ aliquot was mixed with $5 \mu$ l of SDS-PAGE loading dye buffer and $2 \mu$ of dithiothreitol and heated at $70{ }^{\circ} \mathrm{C}$ for $10 \mathrm{~min}$. Subsequently, $10 \mu \mathrm{l}$ aliquots were loaded onto a NuPAGE Novex Bis-Tris (4-12\%) minigel, run at $200 \mathrm{~V}$ under reducing conditions using SDS-MOPS running buffer. When the dye front reached the bottom of gel, electrophoresis was stopped and the gel was carefully removed from the cassette, washed and stained for one hour using Simply Blue stain (Invitrogen Corporation, Paisley, UK) and destained overnight using water.

The secondary structure of BSA in the liposomes following processing was investigated using circular dichroism (CD). The control solution of BSA containing $30 \mu \mathrm{g} / \mathrm{ml}$ was made by dissolving BSA powder into $25 \mathrm{mM}$ Tris $\mathrm{HCl}, \mathrm{pH}=7.2$. Spray-dried uncoated/polymer-coated liposomes were rehydrated with water, followed by ultracentrifugation $(90,000 \mathrm{rpm})$ for 30 minutes. Afterwards, supernatants containing unentrapped BSA were collected and subsequently subjected to centrifugation using Amicon Ultra- $0.5 \mathrm{~mL}$ centrifugal filter (molecular weight cut-off of 100KDa, Millipore, Watford, UK). The filtrate was withdrawn and then concentrated using Amicon Ultra- $0.5 \mathrm{~mL}$ centrifugal filter (molecular weight cut-off of $10 \mathrm{KDa}$, Millipore, as before). The BSA concentration was determined using the HPLC method (as before) then adjusted to $30 \mu \mathrm{g} / \mathrm{ml}$ for CD measurement. Since the interference of TMC and chitosan could not be completely excluded from CD analysis, we adopted an alternative approach to indirectly calculate the maintenance of secondary structure of BSA in chitosan- and TMC-coated liposome following spray drying and rehydration. Data for simulated chitosan- and TMC-coated liposomes encapsulating BSA were obtained from samples produced by following the same preparative procedures of these two polymercoated vesicles but without the inclusion of the polymer excipients. Baseline correction for solvent was made prior to CD analysis of all samples. Spectra were acquired using a Jasco J815 spectropolarimeter (JASCO, Great Dunmow, UK) and using the following settings: cell 
path length $1 \mathrm{~cm}$, band width $1.0 \mathrm{~nm}$, wavelength range 260-190 nm far UV, scanning rate $20 \mathrm{~nm} / \mathrm{min}$, time constant $4 \mathrm{~s}$, wavelength step $0.2 \mathrm{~nm}$. CD spectra for all samples were recorded in an average of 3 scans. Machine units $\Theta_{\text {obs }}$ (millidegrees) were converted to $\Delta \varepsilon$ for secondary structure prediction using Equation 2 (Janda and Casadevall, 2010):

$\Delta \varepsilon=\left(\Theta_{\text {obs }} \times M R W\right) /(10 \times c \times 1 \times 3298)$

Equation 2

Where MRW is the mean residual weight of the BSA (molecular weight/number of amino acids in sequence), $\mathrm{c}$ is the BSA concentration in $\mathrm{mg} / \mathrm{ml}$ and $\mathrm{I}$ is the path length in $\mathrm{cm}$. The extents of secondary structures of BSA (e.g. $\alpha$-helix $\& \beta$-strand) were determined from the delta epsilon $(\Delta \varepsilon)$ using K2D3 software (Louis-Jeune et al 2012).

\subsubsection{Mucoadhesive strength of liposomal powders}

Mucoadhesive strength was determined using a microtensiometer (KRÜSS, Hamburg, Germany) based on the method of Dalpiaz et al., 2008 and Albertini et al. (2009), using bovine nasal mucosa. Briefly, spray-dried powders were compressed into a mini-tablet (weight of $40 \mathrm{mg}$, diameter $0.5 \mathrm{~mm}$ ) by a single punch press(type Korsch, Korsh, Maschinenfabrik No 1.0038.86, Berlin, Germay), attached to the top plate of the instrument and hydrated with $2 \%$ mucin (in $0.9 \% \mathrm{NaCl}, \mathrm{pH} 7.0$ ) solution. The turbinates were fully exposed by a longitudinal incision through the nose and then stored on cold Kreb's Biocarbonate Ringer's (KBR) buffer during transportation to our laboratory. The respiratory mucosa was carefully removed from the underlying bone cutting with scalpel and gently pulling the mucosa off with forceps, washed with KBR solution and cut into small pieces of adequate size. The tissue samples were fixed to the bottom stage of the apparatus with cyanoacrylate adhesive and then hydrated with $2 \%$ mucin solution. The excessive mucin fluid was removed from both nasal mucosa and mini-tablet with tissue paper. The bottom plate Was moved up until minimum contact between nasal mucosa and sample was attained. After one minute rest, the top plate was moved up until the tablet completely detached from mucosa. The force $(p)$ applied to separation of nasal mucosa and min-tablet was recorded on the display $(\mathrm{dyne} / \mathrm{cm})$. This specific force $(p)$ was then transformed into tensile force $\left(T_{\mathrm{F}}\right.$, dyne) using the following equation:

$T_{\mathrm{F}}=p \times 2 \pi r$

Equation 3 
where $r$ is the mini-tablet radius. The detachment force $\left(D_{\mathrm{F}}\right.$, dyne $\left./ \mathrm{cm}^{2}\right)$ was then calculated: dividing the tensile force by the area of the exposed face of the mini-tablet: $D_{\mathrm{F}}=T_{\mathrm{F}} / \pi r^{2}$. The results are reported as mean values \pm S.D. $\left(\mathrm{mN} / \mathrm{cm}^{2}\right)(\mathrm{n}=8)$

\subsubsection{Comparative BSA Release from liposomes}

The dialysis membrane method was used to compare BSA release from the different formulations. Spray-dried powders were dispersed into de-ionized water and then loaded into a dialysis membrane (Spectra/Por CE. Molecular weight cut-off of 300 KDa, Spectrum Laboratories P.V., Breda, Netherlands). The dialysis membrane bag was placed in a vial containing $50 \mathrm{ml}$ of phosphate buffered saline $(\mathrm{pH} 7.2)$ in a shaking incubator $\left(37 \pm 0.5^{\circ} \mathrm{C}\right.$, $60 \mathrm{rpm}, 25 \mathrm{~mm}$ throw; Unitron, Infors HT, Switzerland). At predetermined time intervals, 2 $\mathrm{ml}$ aliquots were withdrawn from the release medium and replaced with conditioned phosphate buffered saline. BSA concentrations were determined using the HPLC method as described above.

\subsubsection{Physicochemical characterisation of spray dried liposome powders}

Modulated temperature differential scanning calorimetry (MTDSC) analysis was performed on the dried powders using a TA Q100 Differential Scanning Calorimeter (TA Instruments, New Castle, PA, USA), which had been calibrated for temperature, enthalpy and heat capacity. Products were sealed into hermetic aluminum pans and after equilibration at $0{ }^{\circ} \mathrm{C}$, were heated at $2{ }^{\circ} \mathrm{C} / \mathrm{min}$ to $250{ }^{\circ} \mathrm{C}$ with a modulation of $\pm 0.4{ }^{\circ} \mathrm{C} / 40 \mathrm{~s}$. Glass transition ( $\mathrm{Tg}$ ) values were recorded as onset values from the reversing heat flow signal. Thermogravimetric analysis was performed to measure the water content of the powders using a TGA (Q500, TA instruments, as before), which had been calibrated for mass and temperature. Samples were heated from 20 to $250{ }^{\circ} \mathrm{C}$ at a scan rate of $10{ }^{\circ} \mathrm{C} / \mathrm{min}$ in an inert nitrogen atmosphere, 3 replicate measurements for each sample were performed.

Morphological examination was performed using SEM; powders were coated in gold with a sputter coater and their surface morphology was observed using a scanning electron microscope (JEOL 6500F field emission scanning electron microscope; JEOL, Tokyo, Japan).

Powder particle size was measured using a Laser Light Diffraction Analyzer (HELOS/BR, Sympatec, Clausthal-Zellerfeld, Germany). Approximately $5 \mathrm{mg}$ of powder was suspended in chloroform in a $50 \mathrm{ml}$ glass cuvette and stirred with a magnetic bar at $1000 \mathrm{rpm}$. A short 
period of sonication (60 s) using an $8.5 \mathrm{~mm}$ diameter ultrasound tip at a power of $60 \mathrm{~W}$ (CUVETTE, Sympatec Clausthal-Zellerfeld, Germany;) was applied before sizing (Minne et al., 2008). A R4 lens was used allowing measurements in the range $0.45-875 \mu \mathrm{m}$. 4 replicate measurements were made for each sample.

\subsubsection{Ex-vivo penetration study across bovine nasal mucosa}

Freshly prepared bovine nasal mucosa was mounted in a Franz-type permeation cell with a diffusional area of $1.5 \mathrm{~cm}^{2}$. To maintain the freshness of the nasal mucosa, the aforementioned process was completed as soon as possible. Material was obtained from freshly slaughtered animals and the experiments were completed within 4 hours of collection (Wadell et al 1999 demonstrated that nasal mucosa remained viable for up to $8 \mathrm{~h}$ after removal). Fresh bovine nasal mucosa obtained from a local slaughter-house was carefully peeled off using forceps, washed with Kreb's Biocarbonate Ringer's solution and cut into small pieces of adequate size. At time zero, sample (either powder or reconstituted liposome dispersion) was loaded into the donor compartment. Powders were carefully spread over the entire surface of the tissue. The receiver compartment filled with Krebs bicarbonate ringer buffer (adjusted to $\mathrm{pH} 7.4$ ) was maintained at $37^{\circ} \mathrm{C}$ by means of a surrounding jacket and constant stirring. Unencapsulated FITC-BSA was used as a control, the amount used was calculated by measuring the total content of FITC-BSA within the respective spray-dried uncoated- and polymer-coated liposome formulations using HPLC, and then adjusting the mass of formulation delivered so that each contained the same mass of FITC-BSA. After $1 \mathrm{~h}$, the formulations were removed from the tissue, which was rinsed twice with further buffer.

For the microscopic analysis, slices perpendicular to the mucosa surface, $10 \mu \mathrm{m}$ in thickness, were cut from the nasal tissue, embedded in the Optimal Cutting Temperature compound, by using a cryostat (Leica CM1900, Wetzlar, Germany) at $-20{ }^{\circ} \mathrm{C}$. Cell nuclei were stained with propidium iodide solution and slides were mounted using polyvinyl alcohol mounting medium with $\mathrm{DABCO}{ }^{\circledR}$ and a cover glass. The slides were observed using confocal laser scanning microscope (CLSM) (BIORAD- $\mu$ Radiance Confocal Scanning System, attached to an Olympus BX-60 microscope (Southend-On-Sea, UK) using $\lambda_{\mathrm{ex}}$ of $485 \mathrm{~nm}$ and $\lambda_{\mathrm{em}}$ of 515 $\mathrm{nm}$ for the visualization of FITC and $\lambda_{\mathrm{ex}}$ of $530 \mathrm{~nm}$ and $\lambda_{\mathrm{em}}$ of $625 \mathrm{~nm}$ for the visualization of propidium iodide. 


\subsubsection{Statistical analysis}

Student's $t$-test and the one-way analysis of variance (ANOVA) with Student-NewmanKeuls all pairwise multiple comparisons were performed to compare two or multiple groups, respectively. Analyses were run using the SigmaPlot 12 software and differences were considered to be significant if $p$ values were in the range 0.01 to 0.05 ; very significant if between 0.001 and 0.01 and extremely significant if $<0.001$.

\section{Results and discussion}

\subsection{Liposomal formulation selection and optimization}

Table 1 shows the effect of different lipid formulations on size and BSA encapsulation efficiency of the freshly prepared suspensions. Formulations of SPC and cholesterol with a 9:2 mole ratio and of SPC:DMPG:cholesterol with a 9:1:2 mole ratio displayed smaller sizes, $<100 \mathrm{~nm}$, than those comprised of SPC: stearylamine: cholesterol (9:1:2 mole ratio). The negative charge associated with the SPC and cholesterol liposomes was attributed to the presence of small percentage of other phospholipids such as phosphatidylserine and phosphatidylinositol that have a negative charge, which has been observed previously (Garg et al., 2007 and Mosca et al. 2011). Although inclusion of stearylamine allowed nearly complete BSA entrapment that was attributed to electrostatic interaction between the positively charged components and the negative charge of the BSA at physiological $\mathrm{pH}(\mathrm{PI} \cong$ 4.7, Lee et al., 2002), , the liposome size markedly increased and phase separation occurred during overnight storage. This was attributed to the very low zeta potential allowing aggregation and fusion (Table 1). Therefore the formulation including negatively charged DMPG was selected for polymer coating and subsequent spray drying.

It has previously been shown that liposomes can be damaged during drying processes and that the addition of disaccharide (protectant) and I-leucine (as an anti-adherent) can prevent powder aggregation (Chen et al., 2012). Therefore the concentration of trehalose in the dispersions was optimized to achieve stable liposomes. Table 2 shows that inclusion of higher concentrations of trehalose offered the best protection to liposomes according to size change and encapsulation efficiency of BSA. It is evident that a combination of $10 \%(w / w)$ trehalose/ $0.2 \%(\mathrm{w} / \mathrm{w})$ leucine in the hydration medium was capable of protecting liposome against spray-drying damage and this protective effect did not appear to markedly increase 
with the increasing concentration of trehalose. Therefore the formulation containing $10 \%$ trehalose and $0.2 \%$ leucine was selected. Although some levels of BSA leakage were found (Table 2), the entrapped efficiency was higher than previous studies (Dhoot and Wheatley, 2003).

\subsection{Characterization of synthesized trimethyl chitosan (TMC)}

Supplementary Figure 1 shows the chemical characteristics of the synthesized TMC compared with chitosan. The IR spectra of chitosan and TMC show a new deformation vibration of $\mathrm{C}-\mathrm{H}\left(\delta_{\mathrm{C}-\mathrm{H}}\left(\mathrm{CH}_{3}\right)\right)$ at $1486 \mathrm{~cm}^{-1}$ in the TMC IR spectrum, indicating that the primary amino groups of chitosan had been substituted by methyl groups, and the successful trimethylation of chitosan. The ${ }^{1} \mathrm{H}-\mathrm{NMR}$ analysis reported in Supplementary Figure 2 revealed that the degree of quaternization of the polymer was $50 \%$. This value is close to the value of $48 \%$ found in the literature by Hamman et al. (2003) to give the best effect on TEER and transport of hydrophilic macromolecules across Caco-2 monolayer cells; higher degrees of quaternization (55\% and 59\%) did not improve these properties, which they attributed to steric hindrance by the additional methyl groups and increased flexibility of the molecules, a similar effect was observed by Boonyo et al. (2007).

\subsection{Characterization of spray-dried liposomes}

The liposome formulation SPC:DMPG:cholesterol (9:1:2 mole ratio) containing $10 \% \mathrm{w} / \mathrm{w}$ of trehalose as protectant and $0.2 \% \mathrm{w} / \mathrm{w}$ of leucine as anti-adherent was coated using $0.25 \%$ $\mathrm{w} / \mathrm{w}$ of alginate and chitosan solutions and $0,5 \% \mathrm{w} / \mathrm{w}$ of TMC solution. The characteristics of spray-dried uncoated/coated liposomes are reported in Table 3 and compared with their properties after reconstitution. After coating liposomes with alginate a small but significant increase in particle size and polydispersity was seen. This was much smaller than the increase observed for chitosan- and TMC-coated liposomes. This difference was attributed to the difference in charge between the polymers. Chitosan and TMC offer the possibility of increased electrostatic interaction with the negatively charged liposome surface, which caused aggregation of the liposomes. A short period of 2.5 min sonication was therefore applied to reduce their size. However after reconstitution, the liposome size increased again, this together with the increase in liposome size and reduction in BSA encapsulation efficiency after spray drying and rehydration indicate that the introduction of polymer into 
the formulation hampered the protective effect of trehalose on the integrity of the liposomes. It has been suggested that interaction between protectants such as trehalose and the polar head groups of the phospholipids at the liposome surface is necessary for a protective effect because of a physical spacing effect that prevents the vesicles from coming into contact with each other (Strauss et al., 1986) and hydrogen bonding between the protectant and lipid head groups (Crowe et al., 1994). Both mechanisms are likely to contribute. Polymer coating can disrupt the trehalose liposome interaction but does not itself offer a specific protective effect thus allowing the liposomes to aggregate/fuse during drying and rehydration (Takeuchi et al 1998); or even for the polymers to become inserted into the liposomal lipid bilayers during rehydration, changing the membrane fluidity and leading to the leakage of entrapped solutes (Dhoot and Wheatley, 2003). As alginate did not cause size increase to the same extent as the other polymers, it is suggested that chitosan and TMC lead to vesicular aggregation through electrostatic interaction and disruption of the interaction between trehalose and the head groups of the phospholipids that is necessary for stabilization.

All of the formulations exhibited excellent encapsulation efficiency before spray drying and the combination of trehalose and leucine in the hydration medium was capable of protecting the uncoated liposomes during spray-drying (Table3). But following spray-drying and rehydration the encapsulation efficiency of the polymer-coating liposomes dropped substantially; the ability to retain BSA decreased in the following order: TMC> chitosan > alginate. Again this was attributed to the polymers interference with the interaction between trehalose and the phospholipids; the better encapsulation efficiency of the positively charged polymers was attributed to their better electrostatic interaction with the negatively charged protein. The period of sonication required for the chitosan and TMCcoated liposomes did not adversely affect the encapsulation efficiency.

\subsection{BSA preservation in the liposomes}

SDS-PAGE analysis (supplementary Figure 3) showed that the structural integrity of BSA loaded into uncoated and polymer-coated liposomes followed by spray-drying and rehydration was preserved. SDS-PAGE analysis reflects changes in the primary structure of protein only, while CD offers additional information about secondary structure. Figure 1 
shows the CD spectra in which two negative bands are visible in the far-UV region at $208 \mathrm{~nm}$ and $222 \mathrm{~nm}$. These are characteristic of the $\alpha$-helical structures of protein (Liu et al., 2004).

Figure 1a shows that the CD spectrum of BSA standard solution almost overlapped with those of uncoated and $0.25 \%$ alginate-coated liposomes, suggesting that the secondary structure of BSA was preserved throughout the coating, drying and rehydration processes. The $\alpha$-helix content of the BSA standard solution was $62.1 \%$, in agreement with the literature (Di Sabatino et al., 2012). The negative control heat treatment at $80^{\circ} \mathrm{C}$ for $1 \mathrm{~h}$ indicates the change in spectrum caused by denaturation (46.3\% $\alpha$-helix content). The $\alpha$ helix content values of BSA loaded into uncoated and $0.25 \%$ alginate-coated liposomes ( $59.8 \%$ and $62 \%$, respectively) were very close to the reference solution (62.1\%)

There was no observed effect of environmental pH on BSA structure (Figure $1 \mathrm{~b}$ ), with $\alpha$ helix contents determined to be $63.1 \%$ in both neutral and acidic pH using the K2D3 software. Furthermore, BSA in simulated TMC- and chitosan-coated liposomes displayed similar spectra to the standard solution with $\alpha$-helix contents determined to be $62.1 \%$ for both coatings. It is suggested that the secondary conformation of BSA in TMC- and chitosancoated liposomes was maintained through spray drying and rehydration. These results indicate the structural integrity of the entrapped BSA in all of the liposomes investigated.

\subsection{Characterization of spray-dried liposome powders}

Spray-dried uncoated and polymer-coated liposome powders displayed sphere-like microparticles with wrinkled surfaces (Figure 2). The size distribution of all dried powders were similar with median particle size by volume in the range of 3-4 $\mu \mathrm{m}$, as reported in Table 4 , indicating that polymer coating had no significant effect on either water content or spray drying properties of the formulations. Additionally, similar acceptably low levels of water content were found for all liposomal powders although the TMC powders exhibited significantly higher $\mathrm{Tg}$ values $(p<0.05)$ than the other formulations, indicating that the inclusion of TMC may also offer a small benefit in terms of thermal stability of the powders. As there were no significant differences in either the particle size or the water content of this formulation compared with the others it is hypothesized that this effect is caused by interaction of the polymer with the trehalose, which is the main contributor to the $\mathrm{Tg}$ of the powder. This effect has not previously been noted for the interaction of TMC with trehalose and may be important in development of TMC containing formulations that require spray or 
freeze-drying.

Figure 3 shows the in vitro release profile of the samples. The dialysis membrane method is used to discriminate between the release profiles of the different liposomal formulations not to mimic in vivo release (Tiwari et al., 2009); the main barrier to release is the dialysis membrane as evidenced by the release profile for BSA alone. $0.25 \%$ alginate-coated and $0.25 \%$ chitosan-coated liposomes exhibited a slightly higher release rate than uncoated and TMC-coated liposomes, although there were no significant differences between any of the coatings nor between coated or uncoated liposomal formulations (Figure 3). The sustained release properties were as expected for liposomal formulations and are preferable to the typical burst release profile that is often displayed by smaller particles, which may lead to protein degradation in the hostile environment of the mucus. Conversely slower release from liposomes protects protein from degradation while it is carried through the mucus.

As regards the mucoadhesion of spray-dried uncoated and polymer-coated liposome powders, chitosan and TMC-coated liposomes exhibited a significantly higher mucoadhesive strength than alginate-coated or uncoated liposomes on the basis of the equivalent mole charge ratio (Figure 4), which was ascribed to the positive charge of chitosan and TMC that can interact with the sialic groups on mucin.

The confocal laser scanning microscopy (CLSM) microphotographs obtained from the ex vivo penetration study show that pure FITC-BSA freely diffused into nasal mucosal tissues after $1 \mathrm{~h}$ penetration (Figure 5a). The uncoated-liposomes (Figure $5 \mathrm{~b}$ and $\mathrm{c}$ ) administered as either powders or reconstituted suspensions, displayed a similar penetration pattern as the FITC-BSA solution. The polymer-coated liposomes exhibited varying ability to penetrate the nasal mucosa. For the alginate-coated liposomes (Figure $5 \mathrm{~d}$ and e), reconstituted suspensions gave an inferior penetration compared to the reconstituted uncoated-liposome suspensions, whilst this effect could be improved by administering as the spray-dried powder. Therefore alginate liposomes performed similarly to the uncoated liposomes when administered both as powder and as liposomal dispersion, showing no advantage as a powder. Chitosan-coated liposomes (Figure $5 \mathrm{f}$ and $\mathrm{g}$ ) exhibited the poorest penetrating ability that was attributed to their increased liposome size after rehydration (Table 3) (Takeuchi et al., 2005) and the reduced solubility of chitosan at a higher pH (Borchard et al., 1996). TMC-coated liposome dispersions (Figure $5 \mathrm{~h}$ ) offered no improvement in 
penetration capability compared with the other formulations presumably due to their increased size, but when the same TMC-coated liposomes were administered as powders (Figure $5 \mathrm{i}$ ) they performed better, possibly because the powders draw water from the nasal mucosa consequently resulting in transient dehydration of epithelial membrane and opening of tight junctions (Callens and Remon, 2000; Dyer et al., 2002; Fernandez-Urrusuno et al., 1999; Illum et al., 2000; Wang et al., 2006). There have been some contradictory effects related to the effect of liposome size reported in the literature (Cao et al., 2009; Jain et al., 2007; Takeuchi et al., 2005). The results obtained in this study suggest that liposome size is of more importance than liposome charge as long as the charge is sufficient to maintain repulsion between the liposome surfaces and prevent aggregation. The benefit of larger liposomes therefore may lie in the improved encapsulation efficiency and thus higher effective concentration of protein at the mucosal membrane. This then acts as a passive driving force for membrane permeation as has been postulated by di Cagno et al. (2013).

Alginate-coated liposomes retained the smallest size after coating and rehydration but chitosan- and TMC-coated liposome powders displayed higher mucoadhesive strength and encapsulation efficiency. All of the spray-dried powders displayed sphere-like morphology with some roughness and similar size regardless of the presence and type of polymers. Among the polymer-coated liposomes, those coated with TMC retained the highest BSA encapsulation $(p<0.05)$. The structure of BSA within the uncoated and polymer-coated liposomes was preserved throughout the preparative process and the polymer coating did not affect the in vitro release rate of the liposomal BSA. A reduction in penetrating ability across bovine nasal mucosa was observed in the reconstituted chitosan- and TMC-coated liposome suspensions, although the TMC-coated liposomes showed a marked improvement when administered as a powder. Taking all of the results together it can be seen that while incorporation into liposomes offered only marginal improvement over FITC-BSA alone, the possibility for improved physicochemical properties e.g. high $\mathrm{Tg}$, encapsulation efficiency and increased mucoadhesion for the TMC-coated liposomes may offer benefits for nasally administered vaccine material especially if administered in a dry powder format.

\section{Conclusions}


For nasally administered products good penetration, is of little use if the formulations are not able to remain in contact with the mucosal surface for a long enough time to enable penetration to occur, therefore mucoadhesion is a key characteristic of a nasally administered formulation where local mucosal delivery is required. Additionally administration of powders rather than liquids enables better storage stability with easier handling and should offer improved stability of the therapeutic payload; all powders exhibited good Tg and water content values. We therefore conclude that although polymer coating resulted in some drug loss and increase in liposomal size, the use of an optimized protectant formulation ensured that the protein was stabilized during manufacture and rehydration. The increased mucoadhesive properties and ability to penetrate the nasal mucosa afforded by the TMC coating outweigh this loss. In vivo studies would be required to determine the importance of mucoadhesion and mucosal penetration in tandem.

\section{Acknowledgements}

We would like to thank Dr. Krit Suknuntha for guidance with TMC synthesis, Dr. Aditya Pattani for help with SDS-PAGE analysis and Dr. Tom Gardiner for his assistance in tissue cryosection and 


\section{References}

Albertini, B., Passerini, N., Di Sabatino, M., Vitali, B., Brigidi, P., Rodriguez, L., 2009. Polymerlipid based mucoadhesive microspheres prepared by spray-congealing for the vaginal delivery of econazole nitrate. Eur. J. Pharm. Sci. 36(, 591-601.

Amidi, M., Romeijn, S.G., Borchard, G., Junginger, H.E., Hennink, W.E., Jiskoot, W., 2006. Preparation and characterization of protein-loaded N-trimethyl chitosan nanoparticles as nasal delivery system. J. Controlled Release. 111, 107-116.

Amidi, M., Romeijn, S.G., Verhoef, J.C., Junginger, H.E., Bungener, L., Huckriede, A., Crommelin, D.J., Jiskoot, W., 2007. N-trimethyl chitosan (TMC) nanoparticles loaded with influenza subunit antigen for intranasal vaccination: biological properties and immunogenicity in a mouse model. Vaccine. 25, 144-153.

Artursson, P., Lindmark, T., Davis, S.S., Illum, L., 1994. Effect of chitosan on the permeability of intestinal epithelial cells (Caco-2). Pharm. Res. 11, 1358-1361.

Avadi, M.R., Zohuriaan-Mehr, M.J., Younessi, P., Amini, M., Tehrani, M.R., Shafiee, A., 2003. Optimized synthesis and characterization of N-triethyl chitosan. J. Bioact. Compt. Polym. 18, 469-480.

Avadi, M.R., Erfan, M., Sadeghi, A.M.M., Moezi, L., Dehpour, A.R., Younessi, P., Tehrani, M.R., Shafiee, A., 2004. N,N, Diethyl N-methyl chitosan as an enhancing agent for colon drug delivery. J. Bioact. Compt. Polym. 19, 421-433.

Bayat, A., Sadeghi, A.M.M., Avadi, M.R., Amini, M., Rafiee-Tehrani, M., Shafiee, A., Majlesi, R., Junginger, H.E., 2006. Synthesis of N-N dimethyl N-ethyl chitosan as a carrier for oral delivery of peptide drugs. J. Bioact. Compt. Polym. 21, 433-444.

Bernkop-Schnurch, A., 2002. Mucoadhesive polymers. In: Dumitriu, S., (Ed). Polymer Biomaterial. Marcel Dekker Inc., New York, pp. 147-165.

Bligh, E.G., Dyer, W.J., 1959. A rapid method for total lipid extraction and purification. Can. J. Biochem. Physiol. 37, 911-917.

Boonyo W, Junginger HE, Waranuch N, Polnok A, Pitaksuteepong T., 2007. Chitosan and trimethyl chitosan chloride (TMC) as adjuvants for inducing immune responses to ovalbumin in mice following nasal administration. J Control Release. 121(3):168-75.

Bonferoni, M.C., Giunchedi, P., Scalia, S., Rossi, S., Sandri, G., Caramella, C., 2006. Chitosan 
gels for the vaginal delivery of lactic acid. Relevance of formulation parameters to mucoadhesion and release mechanisms. AAPS Pharm. Sci. Tech. 7, Article 104.

Borchard, G., Lueßen, H.L., de Boer, A.G., Verhoef, J.C., Lehr, C.M., Junginger, H.E., 1996. The potential of mucoadhesive polymers in enhancing intestinal peptide drug absorption. 3 . Effects of chitosan glutamate and carbomer on epithelial tight junctions in vitro. J. Controlled Release. 39, 131-138.

Braccini, I., Perez, S., 2001. Molecular basis of $\mathrm{Ca}^{2+}{ }_{-}$-induced gelation in alginates and pectins: the egg-box model revisited. Biomacromolecules. 2, 1089-1096.

Callens, C., Remon, J.P., 2000. Evaluation of starch-maltodextrin-carbopol 974 P mixtures for the nasal delivery of insulin in rabbits. J. Control. Rel. 66, 215-220.

Cao, J., Sun, J., Wang, X., Li, X., Deng, Y., 2009. N-Trimethyl chitosan-coated multivesicular liposomes for oxymatrine oral delivery. Drug Dev. Ind. Pharm. 35,1339-1347.

Chen, K.H., Mueannoom, W., Gaisford, S., Kett, V.L., 2012. Investigation into the effect of varying L-leucine concentration on the product characteristics of spray-dried liposome powders. J. Pharm. Pharmacol. 64, 1412-1424.

Crowe, J.H., Leslie, S.B., Crowe, L.M., 1994. Is vitrification sufficient to preserve liposome during freeze-drying? Cryobiol. 31, 355-366.

Dalpiaz A, Gavini E, Colombo G, Russo P, Bortolotti F, Ferraro L, Tanganelli S, Scatturin A, Menegatti E, Giunchedi P. Brain uptake of an anti-ischemic agent by nasal administration of microparticles. J Pharm Sci. 2008. 97(11):4889-903.

Dhoot, N.O., Wheatley, M.A., 2003. Microencapsulated liposomes in controlled drug delivery: strategies to modulate drug release and eliminate the burst effect. J. Pharm. Sci. 92, 679-689. di Cagno M, Luppi B, 2013. Drug “supersaturation” states induced by polymeric micelles and liposomes: A mechanistic investigation into permeability enhancements. Eur. J. Pharm. Sci. 48, 775-780.

Dimova, S., Brewster, M.E., Noppe, M., Jorissen, M., Augustijns, P., 2005. The use of human nasal in vitro cell systems during drug discovery and development. Toxicol. In Vitro. 19, 107122.

Di Sabatino, M., Albertini, B., Kett, V.L., Passerini, N., 2012. Spray congealed lipid microparticles with high protein loading: Preparation and solid state characterisation. Eur. J. Pharm. Sci. 46, 346-356.

Dodane V, Khan MA, Merwin JR. 1999. Effect of chitosan on epithelial permeability and 
structure. Int J Pharm. 182:21-32.

Dyer, A.M., Hinchcliffe, M., Watts, P., Castile, J., Jabbal-Gill, I., Nankervis, R., Smith, A., Illum, L., 2002. Nasal delivery of insulin using novel chitosan based formulations: A comparative study in two animal models between simple chitosan formulations and chitosan nanoparticles. Pharm. Res. 19, 998-1008.

Fernandez-Urrusuno, R., Romani, D., Calvo, P., Vila-Jato, J.L., Alonso, M.J., 1999. Development of a freeze-dried formulation of insulin-loaded chitosan nanoparticles intended for nasal administration. STP Pharma Sci. 9, 429-436.

Garg, M., Dutta, T., Jain, N.K., 2007. Stability study of stavudine-loaded o-palmitoyl anchored carbohydrate-coated liposomes. AAPS PharmSciTech. 8, 1-8.

Gavini, E., Rassu, G., Sanna, V., Cossu, M., Giunchedi, P., 2005. Mucoadhesive microspheres for nasal administration of an antiemetic drug, metoclopramide: in-vitro/ex-vivo studies. J. Pharm. Pharmacol. 57, 287-294.

Gavini, E., Rassu, G., Haukvik, T., Lanni, C., Racchi, M., Giunchedi, P., 2008. Mucoadhesive microspheres for nasal administration of cyclodextrins. J. Drug Target. 17, 168-179.

Gill, I.J., Fisher, A.N., Farraj, N., Pitt, C.G., Davis, S.S., Illum, L., 1998. Intranasal absorption of granulocyte colony stimulating factor (G-CSF) from powder formulations, in sheep. Eur. J. Pharm. Sci. 6, 1-10.

Goldbach, P., Brochart, H., Stamm, A., 1993. Spray-Drying of Liposomes for a Pulmonary Administration. II. Retention of encapsulated materials. Drug. Dev. Ind. Pharm. 19, 26232636.

Hamman, J.H., Schultz, C.M., Kotzé, A.F., 2003. N-trimethyl chitosan chloride: optimum degree of quaternization for drug absorption enhancement across epithelial cells. Drug. Dev. Ind. Pharm. 29, 161-172.

Illum, L., Farraj, N.F., Davis, S.S., 1994. Chitosan as a novel delivery system for peptide drugs. Pharm. Res. 11, 1186-1189.

Ilum, L., Watts, P., Fisher, A.N., Jabbal-Gill, I., Davis, S.S., 2000. Novel chitosan based delivery systems for nasal administration of a LHRH-analogue. STP Pharma Sci. 10, 89-94.

Illum, L., 2003. Nasal drug delivery: possibilities, problems and solutions. J. Controlled Release. 87, 187-198.

Jain, A.K., Chalasani, K.B., Khar, R.K., Ahmed, F.J., Diwan, P.V., 2007. Muco-adhesive multivesicular liposomes as an effective carrier for transmucosal insulin delivery. J. Drug 
Target. 15, 417-427.

Janda, A., Casadevall, A., 2010. Circular Dichroism reveals evidence of coupling between immunoglobulin constant and variable region secondary structure. Mol. Immunol. 47, 14211425.

Kato, Y., Hosokawa, T., Hayakawa, E., Ito, K., 1993. Influence of liposomes on tryptic digestion of insulin. Biol. Pharm. Bull. 16, 457-461.

Law, S.L., Huang, K.J., Chou, V.H.Y., Cherng, J.Y., 2001. Enhancement of nasal absorption of calcitonin loaded in liposomes. J. liposome Res. 11, 164-174.

Lee, V.H., Yamamoto, A., 1990. Penetration and enzymatic barriers of peptide and protein absorption. Adv. Drug Deliv. Rev. 4, 171-207.

Lee, V.H., Yamamoto, A., Kompella, U.B., 1991. Mucosal penetration enhancers for facilitation of peptide and protein drug absorption. Crit. Rev. Ther. Drug Carrier Syst.; 8, 91192.

Lee, W.K., Ko, J.S., Kim, H.M., 2002. Effect of Electrostatic Interaction on the Adsorption of Globular Proteins on Octacalcium Phosphate Crystal Film. J. Colloid. Interface Sci. 246, 70-77. Liu, J., Tian, J., Tian, X., Hu, Z., Chen, X., 2004. Interaction of isofraxidin with human serum albumin. Bioorg. Med. Chem. 12, 469-474.

Louis-Jeune C, Andrade-Navarro MA, Perez-Iratxeta C. Prediction of protein secondary structure from circular dichroism using theoretically derived spectra. Proteins. 2012. 80(2):374-381. K2D3 web-site at http://www.ogic.ca/projects/k2d3/ accessed 14/12/2012

Luppi, B., Bigucci, F., Cerchiara, T., Zecchi, V., 2010. Chitosan-based hydrogels for nasal drug delivery: From inserts to nanoparticles. Exp. Op. Drug Del. 7, 811-828.

Massing, U., Cicko, S., Ziroli, V., 2008. Dual asymmetric centrifugation (DAC)- a new technique for liposome preparation. J. Controlled Release. 125, 16-24.

Minne, A., Boireau, H., Horta, M.J., Vanbever, R., 2008. Optimization of the aerosolization properties of an inhalation dry powder based on selection of excipients. Eur. J. Pharm. Biopharm. 3, 839-844.

Mitra, A.K., Krishnamoorthy, R., 1998. Prodrugs for nasal drug delivery. Adv. Drug Deliv. Rev. $29,135-146$.

Mosca M., Ceglie A., Ambrosone, L., 2011. Effect of membrane composition on lipid oxidation in liposomes. Chem. and Phys. of Lipids, 164, 158-165

Murramatsu, K., Maitani, Y., Takayama, K., Nagai, T., 1999. The relationship between the 
rigidity of the liposomal membrane and the absorption of insulin after nasal administration of liposomes modified with an enhancer containing insulin in rabbits. Drug Dev. Ind. Pharm. $25,1099-1105$.

O'Hagan, D.T., Illum, L., 1990. Absorption of peptides and proteins from the respiratory tract and the potential for development of locally administered vaccine. Crit. Rev. Ther. Drug Carrier Syst. 7, 35-97.

Patil, S.B., Sawant, K.K., 2009. Development, optimization and in vitro evaluation of alginate mucoadhesive microspheres of carvedilol for nasal delivery. J. Microencapsul. 26, 432-43.

Pires, A., Fortuna, A., Alves, G., Falcão, A., 2009. Intranasal drug delivery: how, why, and what for? J. Pharm. Pharm. Sci. 12, 288-311.

Polnok, A., Borchard, G., Verhoef, J.C., Sarisuta, N., Junginger, H.E., 2004. Influence of methylation process on the degree of quaternization of $\mathrm{N}$-trimethyl chitosan chloride. Eur. J. Pharm. Biopharm. 57, 77-83.

Sadeghi, A.M.M., Dorkoosh, F.A., Avadi, M.R., Weinhold, M., Bayat, A., Delie, F., Gurny, R., Larijani, B., Rafiee-Tehrani, M., Junginger, H.E., 2008. Permeation enhancer effect of chitosan and chitosan derivates: Comparison of formulations as soluble polymers and nanoparticulate systems on insulin absorption inCaco-2 cells. Eur. J. Pharm. Biopharm. 70, 270-278.

Sieval, A.B., Thanou, M., Kotze, A.F., Verhoef, J.E., Brussee, J., Junginger, H.E., 1998. Preparation and NMR characterization of highly substituted $\mathrm{N}$-trimethyl chitosan chloride. Carbohydr. Polym. 36, 157-165.

Smith, J., Wood, E., Dornish, M., 2004. Effect of chitosan on epithelial cell tight junctions. Pharm. Res. 21, 43-49.

Stewart, J.C., 1980. Colorimetric determination of phospholipids with ammonium ferrothiocyanate. Anal. Biochem. 104, 10-4.

Strauss, G., Schurtenberger, P., Hauser, H., 1986. The interaction of saccharides with lipid bilayer vesicles: stabilization during freeze-thawing and freeze-drying. Biochim. Biophys. Acta. 858, 169-180.

Takeuchi, H., Yamamoto, H., Toyoda, T., Toyobuku, H., Hino, T., Kawashima, Y., 1998. Physical stability of size controlled small unilamellar liposomes coated with a modified polyvinyl alcohol. Int. J. Pharm. 164, 103-111.

Takeuchi, H., Matsui, Y., Sugihara, H., Yamamoto, H., Kawashima, Y., 2005. Effectiveness of submicron sized, chitosan-coated liposomes in oral administration of peptide drugs. Int. J. 
Pharm. 303, 160-170.

Thanou, M.M., Kotze', A.F., Scharringhausen, T., Luesen, H.L., De Boer, A.G., Verhoef, J.C., Junginger, H.E., 2000. Effect of degree of quaternization of N-trimethyl chitosan chloride for enhanced transport of hydrophilic compounds across intestinal Caco-2 cell monolayers. J. Controlled Release. 64, 15-25.

Thongburisute, K., Takeuchi, H., Yamamoto, H., Kawashima, Y., 2006. Visualization of the penetrative and mucoadhesive properties of chitosan and chitosan-coated liposomes through the rat intestine. J. Liposome Res. 2, 127-141.

Tiwari, S., Goyal, A.K., Mishra, N., Khatri, K., Vaidya, B., Mehta, A., Wu, Y., Vyas, S.P., 2009. Development and characterization of novel carrier gel core liposomes based transmission blocking malaria vaccine. J Controlled Release. 140, 157-65.

Ugwoke, M.I., Agu, R.U., Verbeke, N., Kinget, R., 2005. Nasal mucoadhesive drug delivery: background, applications, trends and future perspectives. Adv. Drug Deliv. Rev. 57, 16401665.

Umrethia, M., Kett, V.L., Andrews, G.P., Malcolm, R.K., Woolfson, A.D., 2010. Selection of an analytical method for evaluating bovine serum albumin concentrations in pharmaceutical polymeric formulations. J. Pharm. Biomed. Anal. 51, 1175-1179.

Wadell C, Björk E, Camber O. Nasal drug delivery--evaluation of an in vitro model using porcine nasal mucosa. Eur J Pharm Sci. 1999. 7(3):197-206.

Wang, J., Tabata, Y., Morimoto, K., 2006. Aminated gelatin microspheres as a nasal delivery system for peptide drugs: Evaluation of in vitro release and in vivo absorption in rats. J. Controlled Release. 113, 31-37. 
Figure captions

Figure 1 (A) CD spectra of BSA standard solution, BSA in uncoated- and $0.25 \%$ alginatecoated, as well as BSA with heat treatment at $80{ }^{\circ} \mathrm{C}$ for $1 \mathrm{~h}$; (B) CD spectra BSA standard in Tris $\mathrm{HCl}$ buffer, $\mathrm{pH}=7.2, \mathrm{BSA}$ standard in acetate buffer, $\mathrm{pH}=5, \mathrm{BSA}$ in simulated chitosan (CHI)-coated and simulated trimethyl chitosan (TMC)-coated liposomes.

Figure 2. SEM images of spray-dried powders of (A) uncoated liposomes; (B) Alginate-coated liposomes; (C) Chitosan-coated liposomes; (D) TMC-coated liposomes.

Figure. 3. Release profiles of BSA from reconstituted uncoated- and polymer-coated liposome suspensions $(0.25 \%$ alginate-coated liposome, $0.25 \%$ chitosan-coated liposome and $0.5 \%$ trimethyl chitosan-coated liposome) through the dialysis membrane over $48 \mathrm{~h}$. Error bars represent standard deviation of three measurements $(n=3)$.

Figure. 4. Comparison of mucoadhesive strength of spray-dried uncoated and polymercoated liposome powders. Each bar represents mean \pm SD of eight measurements $(n=8) . *$ $\mathrm{P}<0.05$ (One Way ANOVA analysis with Student-Newman-Keuls all pairwise multiple comparisons) as compared to uncoated liposome powders, and $+p<0.05$ as compared to $0.25 \%$ alginate-coated liposome powders.

Figure. 5. CCLSM Images showing longitudinal sections of bovine nasal mucosal tissue following $1 \mathrm{~h}$ penetration of a) FITC-BSA solution b) uncoated liposome reconstituted suspension c) uncoated liposome powder d) alginate coated liposome reconstituted suspension e) alginate coated liposome powder f) chitosan liposome reconstituted suspension g) chitosan liposome powder h) TMC-coated liposome reconstituted suspension i) TMC-coated liposome powder Each figure shows overlay of propidium iodide (red) and FITCBSA (green) stain (left) and FITC-BSA stain only (right) 

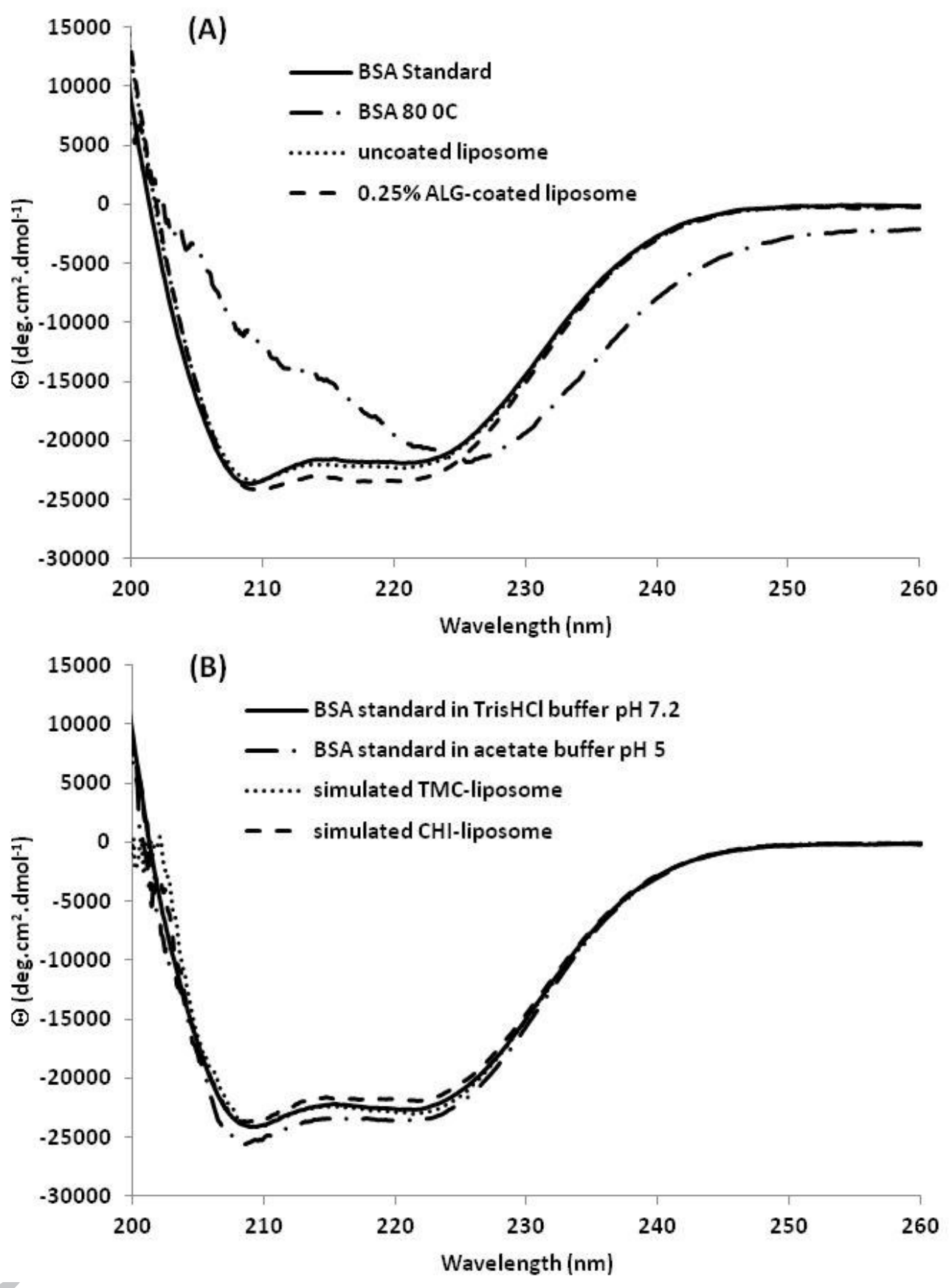

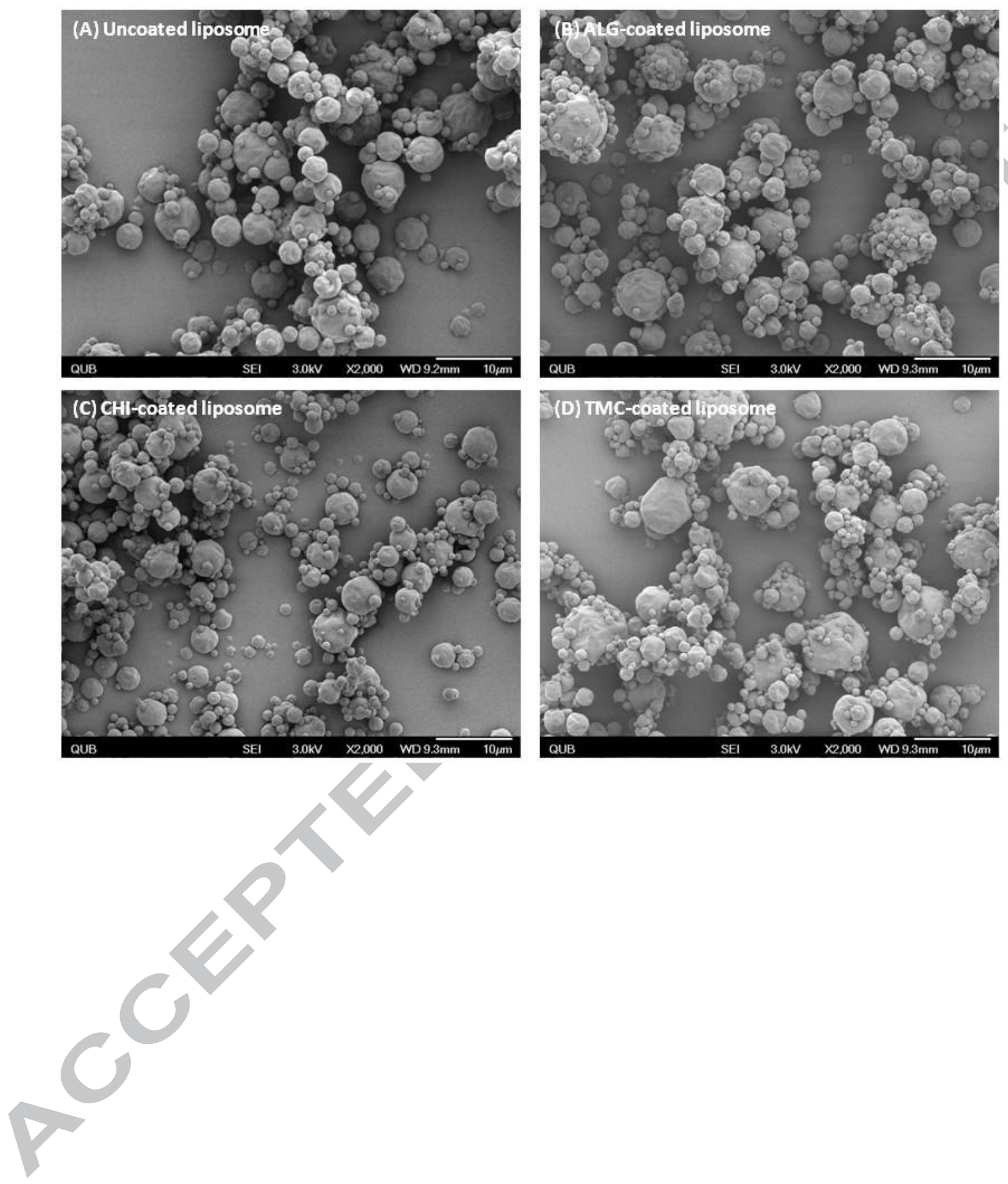


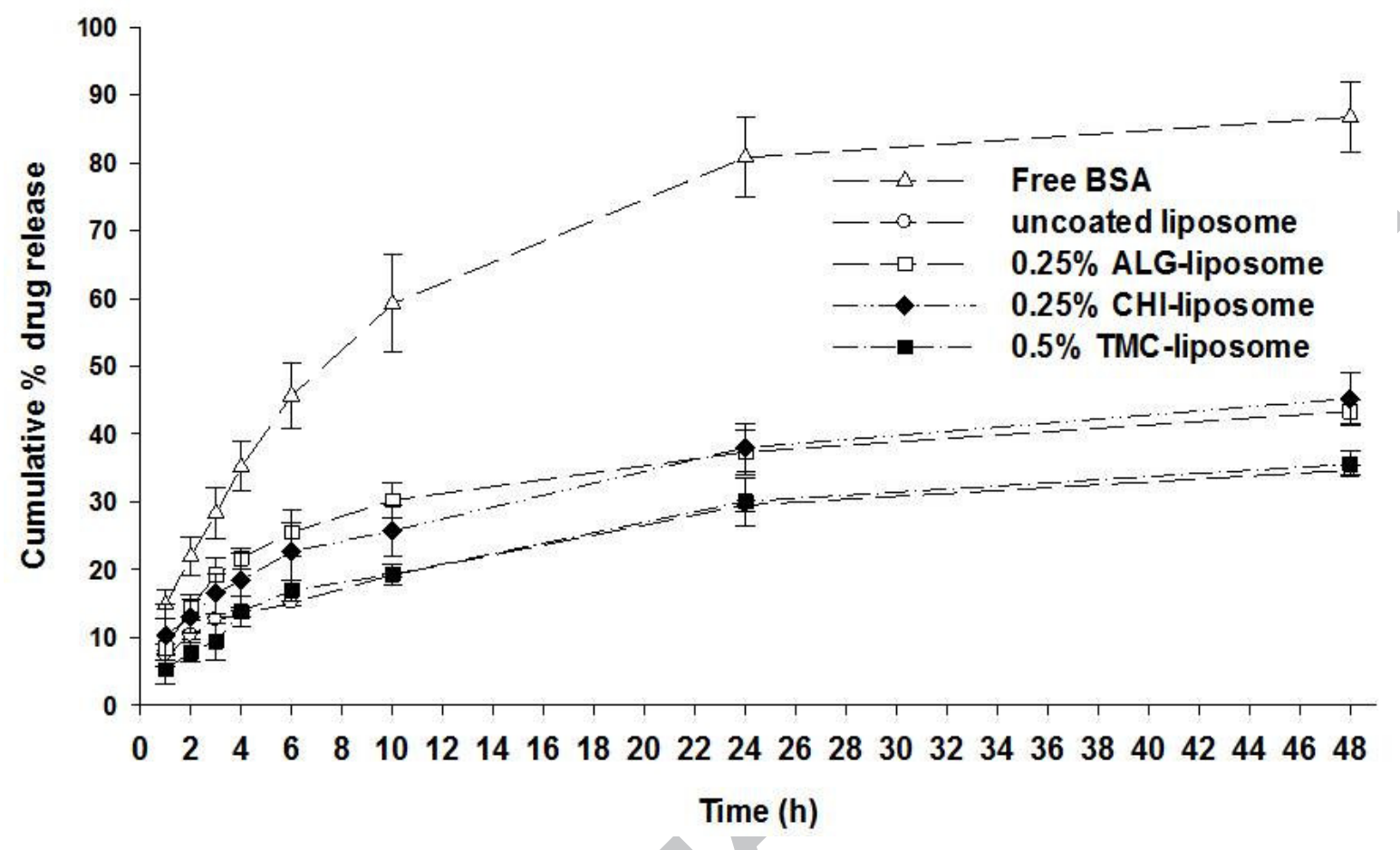




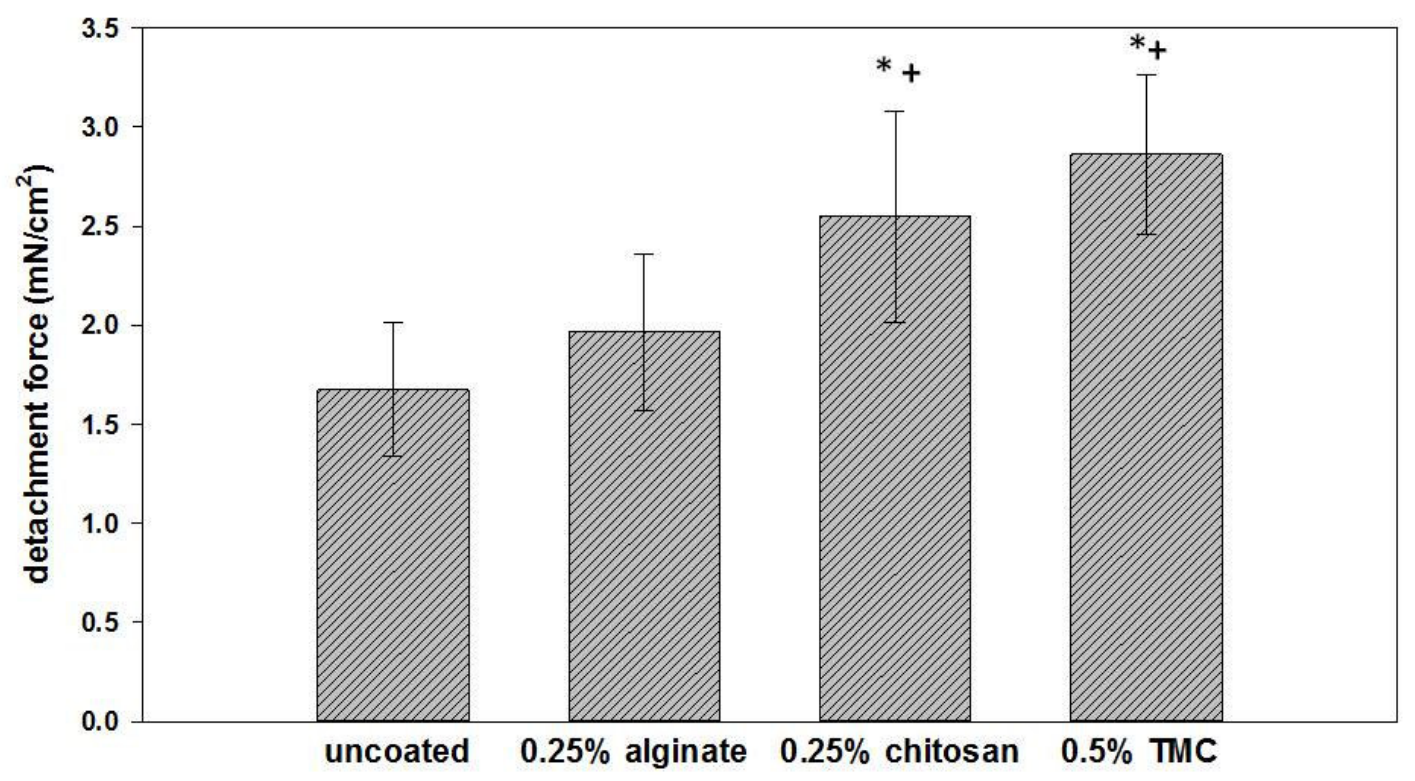

Type of coating 


\section{ACCEPTED MANUSCRIPT}

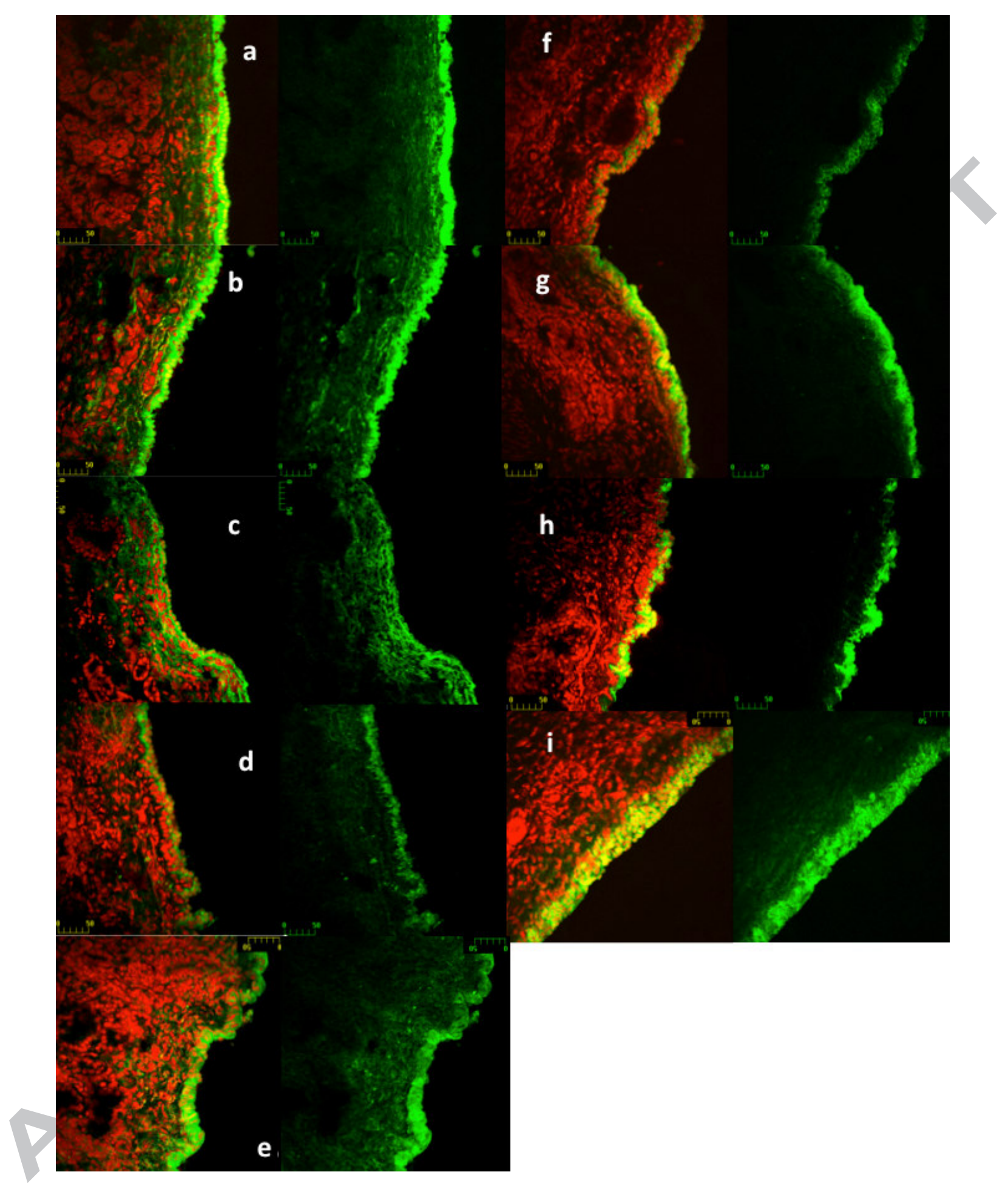


Table 1. Characterization of freshly prepared liposomal suspensions in $25 \mathrm{mM}$ Tris $\mathrm{HCl}$ buffer consisting of differently charged lipids. Values represent mean \pm S.D of three batches and $n$ denotes replicate measurements of each batch. Statistical significance of differences between groups $(P<0.05)$ was determined by one-way ANOVA analysis with StudentNewman-Keuls all pairwise multiple comparisons.

\begin{tabular}{ccccc}
\hline $\begin{array}{c}\text { Formulation } \\
\text { (mole ratio) }\end{array}$ & $\begin{array}{c}\text { Size }(\mathbf{n m}) \\
\boldsymbol{\&} \mathbf{P I}(\mathbf{n}=\mathbf{3})\end{array}$ & $\begin{array}{c}\text { Zeta potential } \\
(\mathbf{m V})(\mathbf{n}=\mathbf{1 0})\end{array}$ & $\begin{array}{c}\text { Total BSA content } \\
(\mathbf{m g} / \mathbf{m l})(\mathbf{n}=\mathbf{2})\end{array}$ & $\begin{array}{c}\text { EE (\%) } \\
\text { \& entrapped BSA (mg/ml) (n=1) }\end{array}$ \\
\hline SPC:CHOL=9:2 & $\begin{array}{c}74.6 \pm 19.0^{*} \\
\left(0.56 \pm 0.14^{*}\right)\end{array}$ & $-21.2 \pm 3.6$ & $2.07 \pm 0.07$ & $\begin{array}{c}69.5 \pm 5.0^{*} \\
\left(1.43 \pm 0.06^{*}\right)\end{array}$ \\
\hline SPC:DMPG:CHOL=9:1:2 & $\begin{array}{c}88.5 \pm 4.1^{*} \\
\left(0.65 \pm 0.05^{*}\right)\end{array}$ & $-42.9 \pm 5.5$ & $1.94 \pm 0.05$ & $72.9 \pm 2.9^{*}$ \\
\hline SPC:SA:CHOL=9:1:2 & $\begin{array}{c}474.7 \pm 206.0 \\
(0.90 \pm 0.18)\end{array}$ & $2.0 \pm 14.6$ & $2.03 \pm 0.17$ & $100.0 \pm 0.2$ \\
\hline
\end{tabular}


Table 2. Characterization of liposomes in the presence of $0.2 \%$ leucine and varying concentrations of trehalose prior to spray-drying and after rehydration. Numbers in parentheses are values after rehydration. Each value represents the mean \pm SD of three batches and $\mathrm{n}$ denotes the number of replicates per batch.

\begin{tabular}{|c|c|c|c|}
\hline & $5 \%$ trehalose & $10 \%$ trehalose & $15 \%$ trehalose \\
\hline \multirow{2}{*}{ Size $(n m)(n=3)$} & $229.7 \pm 10.6^{*}$ & $210.0 \pm 14.1$ & $227.5 \pm 10.3$ \\
\hline & $(285.3 \pm 25.8)$ & $(218.4 \pm 7.2)$ & $(233.5 \pm 9.2)$ \\
\hline \multirow{2}{*}{$\mathrm{PI}(\mathrm{n}=3)$} & $0.06 \pm 0.03^{*}$ & $0.06 \pm 0.03$ & $0.08 \pm 0.05$ \\
\hline & $(0.56 \pm 0.20)$ & $(0.13 \pm 0.06)$ & $(0.11 \pm 0.09)$ \\
\hline \multirow{2}{*}{$\begin{array}{l}\text { Total BSA Content }(\mu \mathrm{g} / \mathrm{ml}) \\
\qquad(\mathrm{n}=2)\end{array}$} & $242.0 \pm 23.3$ & $230.2 \pm 24.9$ & $187.1 \pm 22.1$ \\
\hline & $(247.0 \pm 31.6)$ & $(233.6 \pm 19.1)$ & $(209.9 \pm 9.0)$ \\
\hline \multirow{2}{*}{$\operatorname{EE}(\%)(n=1)$} & $98.0 \pm 0.4$ & $98.4 \pm 1.3^{*}$ & $96.7 \pm 3.4^{*}$ \\
\hline & $(60.7 \pm 4.2)$ & $\left(85.6 \pm 2.4^{+}\right)$ & $\left(88.7 \pm 1.6^{+}\right)$ \\
\hline \multirow{2}{*}{$\mathrm{SPC}$ content $(\mathrm{mg} / \mathrm{ml})(\mathrm{n}=2)$} & $8.13 \pm 0.37$ & $8.29 \pm 0.33$ & $10.35 \pm 0.89$ \\
\hline & $(8.68 \pm 0.49)$ & $(8.66 \pm 0.52)$ & $(10.92 \pm 0.53)$ \\
\hline \multirow{2}{*}{$\begin{array}{c}\text { Loading efficiency } \\
\text { ( } \mu \mathrm{g} B S A / m g \text { lipid) }(n=2)\end{array}$} & $29.2 \pm 2.3^{*}$ & $27.3 \pm 2.0^{*}$ & $17.7 \pm 0.8$ \\
\hline & $(17.2 \pm 1.4)$ & $(23.1 \pm 1.6)$ & $(17.1 \pm 0.6)$ \\
\hline
\end{tabular}


Table 3. Comparison of properties of polymer-coated liposomes prior to spray-drying and after reconstitution. Each value represents mean \pm SD of three batches and $\mathrm{n}$ denotes the number of replicates per batch.

\begin{tabular}{|c|c|c|c|c|c|c|c|c|c|c|}
\hline & \multicolumn{2}{|c|}{ Uncoated liposome } & \multicolumn{2}{|c|}{$0.25 \%$ ALG-coated liposome } & \multicolumn{3}{|c|}{$0.25 \%$ CHI-coated liposome } & \multicolumn{3}{|c|}{ 0.5\% TMC-coated liposome } \\
\hline & \multirow[b]{2}{*}{$\begin{array}{c}\text { Before } \\
\text { spray-drying }\end{array}$} & \multirow{2}{*}{$\begin{array}{c}\text { After } \\
\text { reconstituti } \\
\text { on }\end{array}$} & \multirow[b]{2}{*}{$\begin{array}{c}\text { Before } \\
\text { spray-drying }\end{array}$} & \multirow[b]{2}{*}{$\begin{array}{c}\text { After } \\
\text { reconstitution }\end{array}$} & \multicolumn{2}{|c|}{ Before spray-drying } & \multirow[b]{2}{*}{$\begin{array}{c}\text { After } \\
\text { reconstitution }\end{array}$} & \multicolumn{2}{|c|}{ Before spray-drying } & \multirow[b]{2}{*}{$\begin{array}{c}\text { After } \\
\text { reconstitution }\end{array}$} \\
\hline & & & & & $2 \mathrm{hr}$ coating & $\begin{array}{c}2.5 \text { min } \\
\text { sonication }\end{array}$ & & 2hr coating & $\begin{array}{c}2.5 \mathrm{~min} \\
\text { sonication }\end{array}$ & \\
\hline Size $(n m)(n=3)$ & $210.0 \pm 14.1$ & $218.4 \pm 7.2$ & $268.1 \pm 12.3$ & $303.3 \pm 10.0^{* \star}$ & $902 . \pm 185.2^{+}$ & $\begin{array}{c}354.3 \pm \\
15.4 \\
\end{array}$ & $996.4 \pm 68.1^{+*}$ & $2264.2 \pm 281.4^{+\#}$ & $316.0 \pm 9.7$ & $\begin{array}{c}848.7 \pm \\
203.0^{+*}\end{array}$ \\
\hline PI $(n=3)$ & $0.06 \pm 0.03$ & $0.13 \pm 0.06^{*}$ & $0.42 \pm 0.11$ & $0.45 \pm 0.06^{*}$ & $0.95 \pm 0.14^{+}$ & $0.32 \pm 0.09$ & $1.00 \pm 0.00^{+\infty}$ & $1.00 \pm 0.00^{+}$ & $0.10 \pm 0.07$ & $1.00 \pm 0.00^{+*}$ \\
\hline $\begin{array}{l}\text { Zeta potential } \\
(\mathrm{mV})(\mathrm{n}=10)\end{array}$ & $-49.7 \pm 3.3$ & $-54.6 \pm 2.6^{*}$ & $-54.2 \pm 1.8$ & $-60.3 \pm 1.2^{*}$ & $42.8 \pm 3.3$ & $42.7 \pm 1.0$ & $44.0 \pm 1.8^{+}$ & $36.1 \pm 2.6^{\#}$ & $35.0 \pm 1.1$ & $32.7 \pm 1.4^{+}$ \\
\hline $\begin{array}{c}\text { Total BSA } \\
(\mu \mathrm{g} / \mathrm{ml})(\mathrm{n}=2)\end{array}$ & $230.2 \pm 24.9$ & $233.6 \pm 19.1$ & $257.3 \pm 12.1$ & $247.4 \pm 7.2$ & $239.5 \pm 30.2$ & $\begin{array}{c}241.6 \pm \\
27.5\end{array}$ & $244.5 \pm 26.9$ & $278.1 \pm 22.5$ & $\begin{array}{c}262.4 \pm \\
16.6\end{array}$ & $271.3 \pm 12.3$ \\
\hline $\mathrm{EE}(\%)(\mathrm{n}=1)$ & $98.4 \pm 1.3$ & $85.6 \pm 2.4^{*}$ & $99.2 \pm 0.0$ & $61.3 \pm 4.8^{* \star 2}$ & $97.8 \pm 0.5^{+\#}$ & $89.2 \pm 0.9$ & $60.7 \pm 1.0^{+*}$ & $97.5 \pm 1.0^{+\#}$ & $87.6 \pm 2.6$ & $69.2 \pm 3.2^{+*}$ \\
\hline $\begin{array}{c}\text { SPC content } \\
(\mathrm{mg} / \mathrm{ml})(\mathrm{n}=2)\end{array}$ & $8.29 \pm 0.33$ & $8.66 \pm 0.51$ & $7.93 \pm 0.53$ & $8.57 \pm 0.31$ & $8.82 \pm 0.66$ & $8.74 \pm 0.74$ & $9.12 \pm 0.56$ & $8.78 \pm 0.67$ & $8.64 \pm 0.63$ & $9.29 \pm 0.79$ \\
\hline $\begin{array}{c}\text { Loading } \\
\text { efficiency ( } \mu \mathrm{g} \\
\text { BSA/mg lipid) } \\
(\mathrm{n}=2)\end{array}$ & $27.3 \pm 2.0$ & $23.1 \pm 1.6^{*}$ & $32.3 \pm 3.6$ & $17.7 \pm 1.7^{*}$ & $26.8 \pm 5.2^{\#}$ & $24.8 \pm 3.8$ & $16.4 \pm 2.7^{+}$ & $31.0 \pm 3.9^{\#}$ & $26.7 \pm 2.6$ & $20.3 \pm 2.0^{+}$ \\
\hline
\end{tabular}

$* \mathrm{P}<0.05$ (t-test) comparison of formulation prior to spray-drying and after rehydration.

$+\mathrm{P}<0.05$ (One Way ANOVA analysis with Student-Newman-Keuls all pairwise multiple comparisons) as compared to the corresponding formulations after 2.5-min sonication.

\# P $<0.05$ (One Way ANOVA analysis with Student-Newman-Keuls all pairwise multiple comparisons) as compared to their reconstituted liposomes.

* $\mathrm{P}<0.05$ (One Way ANOVA analysis with Student-Newman-Keuls all pairwise multiple comparisons) as compared to reconstituted uncoated liposomes. 
Table 4. Size distribution, water content and Tg values of spray-dried uncoated and polymercoated liposome powders. Each value represents mean \pm SD of three batches and $n$ denotes replicate measurements of each batch.

\begin{tabular}{|c|c|c|c|c|c|c|}
\hline & \multicolumn{4}{|c|}{ Particle size distribution } & \multirow[b]{2}{*}{$\begin{array}{c}\text { Water content } \\
(\%)(n=3)\end{array}$} & \multirow[b]{2}{*}{$\operatorname{Tg}\left({ }^{0} \mathrm{C}\right)(\mathrm{n}=3$} \\
\hline & $d[v, 10] \mu \mathrm{m}$ & $d[v, 50] \mu \mathrm{m}$ & $\mathrm{d}[\mathrm{v}, 90] \mu \mathrm{m}$ & $\begin{array}{l}\text { SPAN } \\
(n=4)\end{array}$ & & \\
\hline Uncoated liposome & $1.18 \pm 0.01$ & $3.89 \pm 0.05$ & $8.68 \pm 0.18$ & $1.93 \pm 0.02$ & $3.2 \pm 0.2$ & $60.4 \pm 0.9$ \\
\hline ALG- liposome & $1.18 \pm 0.01$ & $3.86 \pm 0.02$ & $8.58 \pm 0.09$ & $1.92 \pm 0.01$ & $3.2 \pm 0.2$ & $60.1 \pm 0.9$ \\
\hline CHI- liposome & $1.17 \pm 0.01$ & $3.84 \pm 0.03$ & $8.52 \pm 0.11$ & $1.91 \pm 0.01$ & $3.5 \pm 0.2$ & $58.6 \pm 1.7$ \\
\hline TMC- liposome & $1.18 \pm 0.01$ & $3.92 \pm 0.04$ & $8.82 \pm 0.14$ & $1.95 \pm 0.01$ & $3.3 \pm 0.3$ & $64.3 \pm 2.3$ \\
\hline
\end{tabular}


Graphical abstract

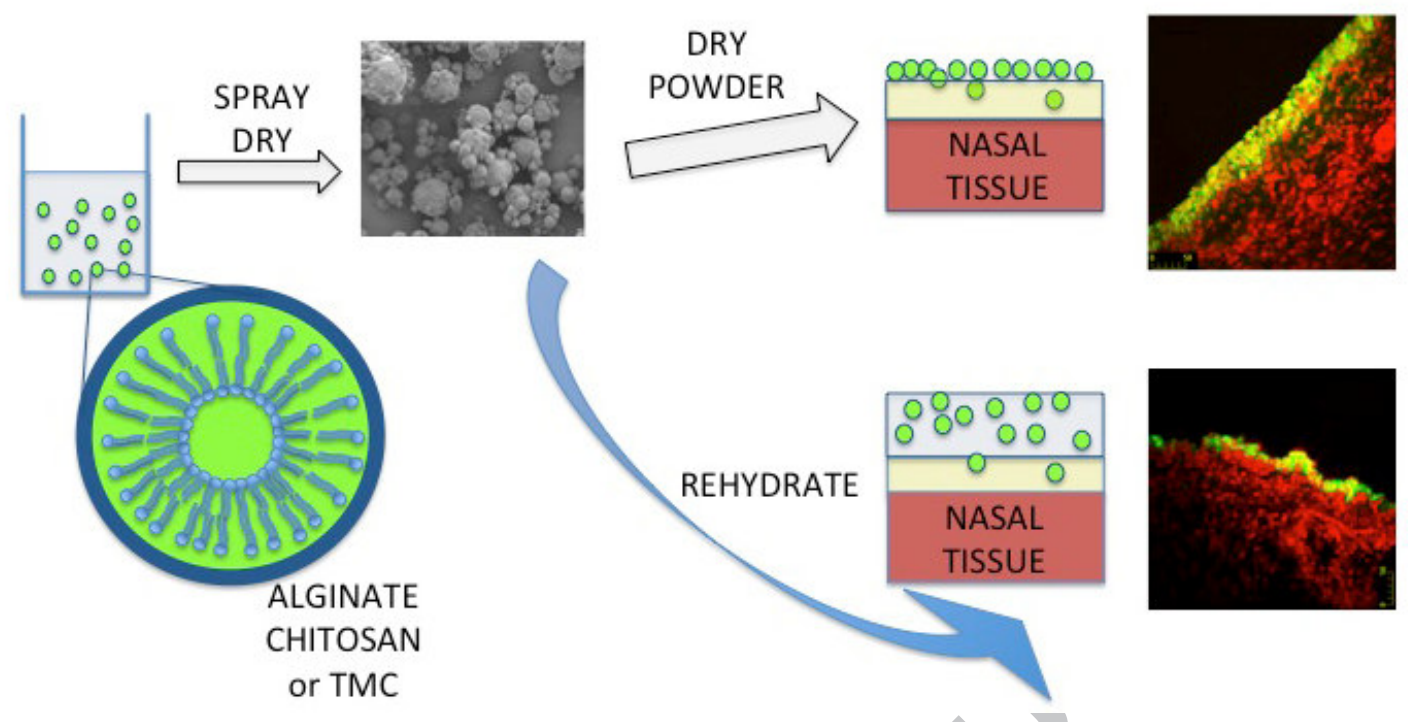

